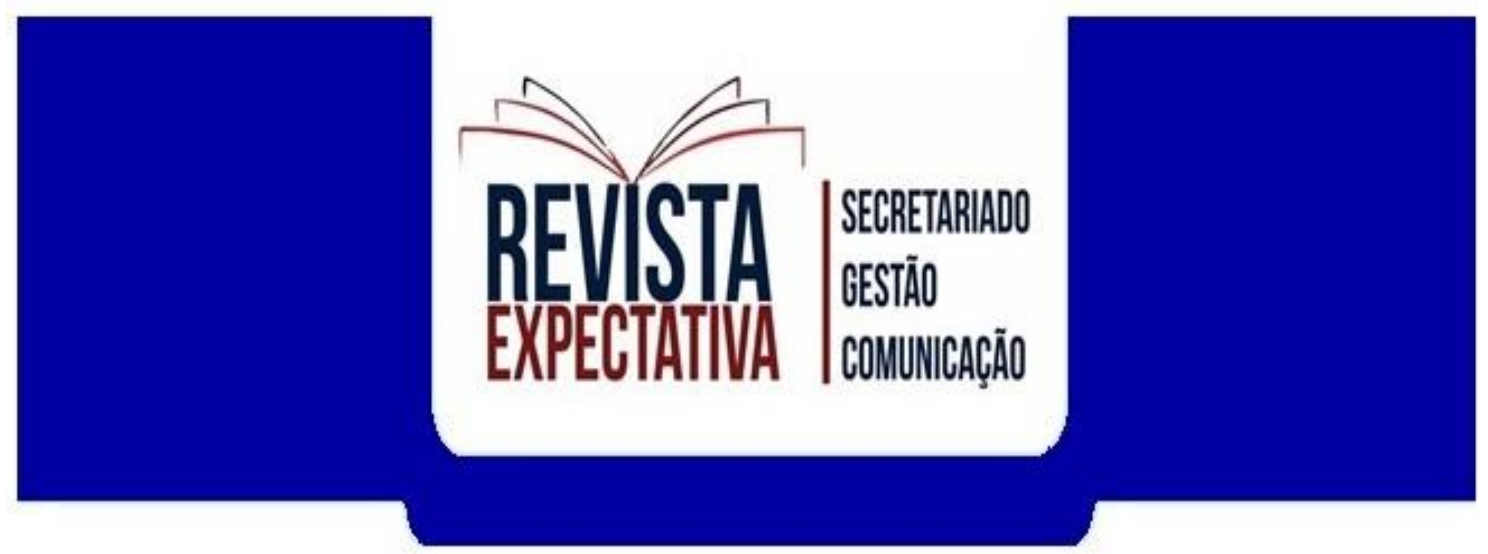

\title{
SATISFAÇÃO NO ATENDIMENTO: UM ESTUDO DE CASO EM UMA EMPRESA DO MUNICÍPIO DE CAPELA (SE)
}

Maria Gisleine Silva Marques ${ }^{1}$, Nathalia Carvalho Moreira², Silvia Regina Paverchi ${ }^{3}$

Resumo: Este trabalho teve como objetivo geral analisar a percepção dos clientes a respeito do atendimento em uma empresa privada. Tratou-se de um estudo de caso, do tipo descritivo, utilizando como técnica de coleta de dados um questionário estruturado aplicado a 80 clientes para averiguar os níveis de satisfação quanto ao atendimento recebido, aos produtos/serviços e ambiente da empresa. Como local de estudo, foi escolhida de forma intencional, uma empresa do setor de serviços localizada no município de Capela, estado de Sergipe (SE). Dentre os principais resultados, pode-se verificar o grau de satisfação dos clientes; o que possibilita criar melhores estratégias que busquem satisfazê-los e mantê-los fiéis a empresa. Por fim, foi possível identificar pontos negativos, especialmente na questão preço, pois para os clientes é perceptível observar a insatisfação, relacionada à falta de descontos oferecidos pela empresa. Assim, a empresa deve rever seu posicionamento perante este quesito, para que assim, possa melhor satisfazer seus clientes e crescer no mercado.

Palavras-chave: Atendimento ao cliente. Satisfação no atendimento. Produtos e Serviços.

\footnotetext{
1 Bacharel em Secretariado Executivo pela Universidade Federal do Sergipe. https://orcid.org/0000-0001-9935-3348

2 Doutora em Administração Pública e Governo pela Fundação Getúlio Vargas (EAESP/FGV 2016). Graduada em Secretariado Executivo Trilíngue (UFV - 2007). Professora do curso Secretariado Executivo na Universidade Federal de Sergipe (UFS). https://orcid.org/0000-00026690-6652

${ }^{3}$ Doutora pelo Programa de Integração da América Latina (PROLAM/USP). Graduada em Secretariado Executivo Bilíngue (PUCSP). Professora do curso Secretariado Executivo na Universidade Federal de Sergipe (UFS). https://orcid.org/0000-0002-0837-0634
}

Editor: Cezar Roberto Versa

Recebido em: 21/12/2019 - Revisado em: 15/03/2020 - Aprovado em: 21/04/2020

Revista Expectativa- e-ISSN 1982-3029 - v.19 - n.1 - jan./jun. - 2020 
Abstract: This work had as general objective to analyze the perception of the clients regarding the service in a private company. It was a descriptive case study, using as a data collection technique a structured questionnaire applied to 80 clients to ascertain the levels of satisfaction regarding the service received, the products / services and the company's environment. As a study site, a service company located in the municipality of Capela, state of Sergipe (SE), was intentionally chosen. Among the main results, one can verify the degree of customer satisfaction; which makes it possible to create better strategies that seek to satisfy them and keep them faithful to the company. Finally, it was possible to identify negative points, especially in the price issue, since it is noticeable for customers to observe the dissatisfaction, related to the lack of discounts offered by the company. Thus, the company must review its position in this regard, so that, it can better satisfy its customers and grow in the market.

Keywords: Customer service. Satisfaction in service. Products and services.

\section{INTRODUÇÃO}

De acordo com Bentes (2010), é fundamental que as organizações possuam competências exigidas pelo mercado para atender e satisfazer o cliente, e para isso, é preciso ter qualidade em vários segmentos como: produtos diferenciados, agilidade, valores, e, sobretudo no atendimento.

Possuir um atendimento satisfatório ajuda a oferecer bons serviços pela empresa. De acordo com Dantas (2010), o atendimento deve estar ligado ao bom fornecimento de produtos, aos serviços e a um relacionamento amigável por parte de quem os oferece.

Portanto, a qualidade no atendimento ao cliente é uma ferramenta importante para fidelização dos mesmos, principalmente para as empresas que buscam conseguir destaque frente à concorrência em um mercado cada dia mais competitivo. Sendo assim, a satisfação do consumidor torna-se um fator importante para que as empresas possam manter-se firmes e crescentes, e isso, requer mais empenho para servir bem e com qualidade.

Para Bentes (2010), há uma necessidade de saber entender as necessidades dos clientes. Isso não é um trabalho impossível, porém pode ser 
difícil e se a empresa não se preocupar com isto, os concorrentes poderão identificar melhores alternativas de conquistar os clientes.

Dessa forma, as organizações precisam observar seus consumidores, pois são os clientes que avaliam a qualidade do atendimento, adquirem produtos e a satisfação do cliente é garantia de retorno, e logo, progresso para a empresa. Em outras palavras: o bom atendimento é garantia de qualidade, como define Las Casas (2006, p. 89) que "a qualidade em serviços está ligada à satisfação", ou seja, cliente satisfeito é garantia de sua volta à organização.

O pontapé inicial para a realização desta pesquisa partiu da observação da pesquisadora em seu local de trabalho ao perceber que no dia-a-dia alguns clientes mostravam-se insatisfeitos com o atendimento recebido pela empresa e faziam críticas relacionadas ao atendimento em geral. Devido a isso, despertou-se o interesse em compreender o que os levou tais comentários, quais os motivos da insatisfação e quais as providências que podem ser tomadas diante do ocorrido, para que, isso não ocorra com frequência, podendo traçar alternativas e soluções de melhorias. Nesse contexto, emergiu o seguinte questionamento: Qual a percepção dos clientes a respeito do atendimento recebido em uma organização privada do município de Capela, estado de Sergipe?

Logo, a presente pesquisa teve como objetivo identificar o que leva 0 cliente a estar (in) satisfeito com o atendimento recebido dentro da empresa. Para tanto, como local de estudo, foi escolhida de forma intencional, a referida empresa que atua no segmento do setor de serviços e possui médio porte.

A partir destas reflexões iniciais, pode-se inferir a seguinte premissa: as críticas mencionadas podem estar relacionadas a diversos fatores tais como: falhas no atendimento, os serviços/produtos oferecidos, o ambiente, relacionamento, entre outros.

Conforme Las Casas (2006, p.89), a qualidade e satisfação dos serviços oferecidos são favoráveis, pois um cliente ao estar satisfeito é um resposta positiva dos serviços o qual recebeu da organização, isso se dá pelo fato do cliente ser suprido de sua necessidade por intermédio da solução de um problema ou outro motivo que o levou a utilizar os serviços oferecidos pela mesma. 
Para Bentes (2010), em geral as empresas buscam melhorias em seus serviços para melhor atender sua clientela, para com isso, conquistar um grande marketing para a empresa, a divulgação boca-a-boca que é um instrumento de feedback em que demonstra que a empresa oferece atendimentos satisfatórios, dessa forma a empresa, ao identificar as necessidades, é o que os mantém satisfeitos com relação aos serviços e o atendimento prestado, faz com que o cliente retorne e ainda traga mais outros clientes.

Para a área acadêmica, esta pesquisa poderá contribuir para o conhecimento mais aprofundado a pesquisas ligadas às empresas, contribuindo para o desenvolvimento deste campo de pesquisa, especialmente da área de Secretariado Executivo, profissão que dentre suas atribuições atua constantemente com atendimento ao público em organizações. Dessa forma, a pesquisa é favorável ao conhecimento sobre as necessidades, falhas e satisfação no atendimento que o cliente recebe dentro da empresa, e com isso, buscará melhorias no seu atendimento e em seus serviços/produtos oferecidos.

Estudos recentes tem aprofundado o debate, como por exemplo, Machado et al. (2013) que examinaram a satisfação no atendimento; e Antunes et al. (2012) que analisaram a implementação do pós-venda em uma organização; ambos tiveram como locais de estudo organizações do estado do Paraná. Ademais, Pereira e Moreira (2015) realizaram uma avaliação bibliométrica dos periódicos científicos nacionais entre os anos 1997 e 2013; e concluíram que o tema Qualidade no Atendimento apesar de sua importância não esteve em evidência durante esses anos, tendo sido encontrados poucos trabalhos publicados em periódicos indexados. Além disso, os referidos autores observaram que os autores mais citados nas referências são de nacionalidade estrangeira. A partir dessas observações, confirma-se a abertura de um campo de pesquisas crescente, em que o Secretariado Executivo pode se dedicar.

Este artigo está dividido em seis partes. Inicialmente, apresenta-se esta breve introdução. Em sequência, é apresentada a fundamentação teórica com os principais autores consultados. Em terceiro lugar, a metodologia que foi utilizada para a coleta de dados necessários a desenvolver a pesquisa. Em seguida, a análise e discussão dos resultados. Por fim, as considerações finais 
e sugestões para estudos futuros.

\section{REFERENCIAL TEÓRICO}

\subsection{COMPREENDENDO O CONCEITO DE SERVIÇOS}

Os conceitos de "serviços" são diversos, sendo assim, é interessante abordar seu significado para melhor compreender todo o contexto do tema.

Para Las Casas (1998 apud Dantas 2010), serviço é "a transação realizada por uma empresa ou indivíduo, cujo objetivo não está relacionado à transferência de um bem". O serviço está vinculado a pessoas e quando o assunto é atendimento, essa abordagem é relacionada ao cliente.

Kotler (2002) define serviço como "uma ação, desempenho ou ato que é essencialmente intangível e não acarreta necessariamente a propriedade do que quer seja".

Segundo Las Casas (2006), perceber a qualidade de uma prestação de serviço por meio do contentamento do cliente é uma das formas de identificar o nível de satisfação. A empresa deve ter a cautela em planejar os serviços oferecidos, para oferecer um serviço eficiente. Sendo assim, os clientes retornarão e ainda indicarão para outras pessoas.

Há influências que podem causar impacto ao cliente, no momento o qual o serviço é oferecido. Segundo Dantas (2010, p. 13), "cada fator exige cuidado específico, em função de sua importância na percepção de valor que pode gerar no cliente".

Dantas (2010) afirma que o local onde os serviços são prestados tem que ser o mais agradável possível, uma empresa que oferece um ambiente bem cuidado, sinalizado, limpo, funcional pode contribuir diretamente na satisfação do cliente, causando nele uma imagem apropriada da empresa.

Outro fator também é a organização e sistemas inviáveis. Dantas (2010) menciona que a prestação de serviços, deve ser proposta ao cliente com qualidade, oferecendo assim, uma sensação de confiabilidade e de serenidade, não podendo confundir as regras da empresa com excesso de burocracia e fluindo de forma mais rápida sem causar contratempos ou morosidade.

Em relação ao fator prestador de serviços, Dantas $(2010$, p. 14) afirma 
que: "as pessoas que atendem não podem ser pessoas despreparadas. Estas devem ser predispostas ao atendimento, conhecer o que fazem, gostar de lidar com pessoas, ser educadas e corteses; e principalmente saber negociar".

E por fim, o "outro cliente" para Dantas (2010) é tão importante quanto as demais influências com serviços, pois o fracasso ou sucesso pode estar nos mesmos. Interessante notar que, mesmo tendo o conhecimento da importância do cliente para o seu crescimento, as empresas não possuem o hábito de colocar em prática alguns desses fatores.

\subsection{ATENDIMENTO AO CLIENTE}

O cliente é uma das peças importantes para o crescimento da empresa, é ele quem adquire os serviços/produtos oferecidos pela mesma, pois é o consumidor direto. Dantas (2010) define o cliente como o rei, afirma que o cliente tem sempre razão, que está sempre em primeiro lugar, que o cliente é a razão de ser da empresa. Kotler (2000) observa que clientes satisfeitos têm chances elevadas de se tonar um cliente fiel, pois a satisfação está ligada ao nível de atendimento oferecido pela empresa, e assim, o cliente pode retornar à empresa, pois percebem que seu dinheiro (compra) é valorizado. Portanto, o cliente satisfeito sempre retorna em busca dos melhores serviços/produtos.

Nesse âmbito, a empresa deve buscar melhorar seus serviços, e de tal modo, atender bem seus clientes, para que sua posição de competitividade no mercado aumente, e para isso, é preciso que a empresa conheça mais sobre os seus consumidores para oferecer uma oferta diferenciada, focando nas suas necessidades e desejos. A qualidade em atender bem ao cliente é favorável para a empresa. A empresa que oferece um atendimento agradável, sempre sairá na frente.

Por outro lado, Costa, Nakata e Calsani (2013) afirmam que:

Um bom atendimento leva a organização e colaboradores ao
sucesso. No contexto empresarial, pode-se considerar que a
qualidade é essencial no desenvolvimento de um trabalho, isso
relacionado a todos os aspectos que envolvem desde a produção e a
prestação de serviços. No entanto, nem todas as empresas fazem
disso, uma prática. Pensar somente no lucro sem qualidade é pensar
curto prazo. Os clientes querem cada vez mais qualidade nos 
produtos e serviços. (COSTA; NAKATA e CALSANI, 2013).

Dantas (2010) discorre sobre o modelo ideal de atendimento, baseado no que o cliente quer. $O$ referido autor sintetiza um modelo com quatro itens importantes. De acordo com Dantas (2010, p. 60), "o atendimento pode ser caracterizado basicamente pelos atendentes, pelo tratamento dispensado ao cliente e pelo ambiente".

No Quadro 1, poderemos ver esse modelo "ideal" resumidamente:

Quadro 1 - Modelo ideal de atendimento.

\begin{tabular}{l|l}
\hline Fatores & Características \\
\hline Fatores fundamentais & $\begin{array}{l}\text { Cortesia, simpatia, educação, cumprimento de promessas e } \\
\text { ofertas, desburocratização. }\end{array}$ \\
$\begin{array}{l}\text { Satisfação passada para o } \\
\text { cliente }\end{array}$ & $\begin{array}{l}\text { Sempre bem-vindos, problemas são tratados por seres } \\
\text { humanos, não possui argumentações falsas } \\
\text { Ogir como empresa e pensar como cliente, conhecer bem os } \\
\text { produtos/serviços da empresa, conhecer técnicas de } \\
\text { relacionamento humano, ter capacidade e autonomia para } \\
\text { resolver problemas, tratar o cliente como gostaria de ser } \\
\text { tratado. }\end{array}$ \\
O ambiente de atendimento & $\begin{array}{l}\text { Limpo, bem decorado, bem sinalizado, atendentes bem } \\
\text { selecionados e treinados, confortável para clientes e } \\
\text { atendentes. }\end{array}$ \\
\hline
\end{tabular}

Fonte: Dantas (2010).

Logo, um cliente satisfeito é um cliente que sempre retorna a organização tornando-se um divulgador fiel dos serviços oferecidos e sendo diretamente um colaborador para o marketing "boca-a-boca" da organização.

Costa, Nakata e Calsani (2014, p. 16) consideram de forma simples que o cliente é uma pessoa que compra produtos da empresa, para próprio consumo, ou para distribuir estes produtos para consumidores finais, como a pessoa mais importante em qualquer tipo de negócio. Algumas habilidades ajudam a atender bem os clientes, como vendas eficazes, saber ouvir e diagnosticar as necessidades.

a) atender necessidades de benefícios é vender os benefícios que os produtos oferecem para atender as necessidades dos clientes.

b) saber ouvir - Saber ouvir as necessidades dos clientes é algo importante, e isso é necessário ser desenvolvido constantemente.

c) saber diagnosticar as necessidades dos clientes - Interagir e buscar ter uma relação mais próxima ao cliente, gera uma forma de intimidade passando a conhecer o que ele pensa e como age, levando assim, ao conhecimento das suas devidas necessidades, já que os clientes cada dia mais se tornam exigentes. (BENTES, 2010, 
p. 33).

Como podemos observar, compreender o cliente e identificar suas necessidades, torna-se viável e crucial para a organização. Coletar informações, ouvir e atender suas necessidades são atitudes favoráveis e imprescindíveis para cativá-los e consequentemente, ajudar no crescimento da empresa. Las Casas (2006, p. 99) recomenda dez lições que ajudam na prática de serviços favoráveis à organização. Segue a sequência dessas práticas que podem ajudar a organização.

1) A primeira delas é ouvir - aperfeiçoar esse serviço é decorrente do aprendizado contínuo, de entender o cliente;

2) A segunda é confiabilidade - o cliente ao confiar no prestador de serviço obtém segurança, e se isso não ocorrer não terá interesse;

3) A terceira é o serviço básico - os clientes querem realmente os serviços divulgados e não algo que não possa estar disponível;

4) A quarta é o projeto de serviços - os serviços devem ser criados e ao ter algum tipo de falha devem ser identificadas e buscarem ser corrigidas;

5) A quinta é a recuperação - as falhas e reclamações dos clientes devem ser corrigidas imediatamente, para não criar clientes insatisfeitos;

6) A sexta é surpreender clientes - tratar o cliente com atendimento devido é satisfatório, caso não gerará insatisfação.

7) A sétima é o jogo justo - tratar os clientes de forma justa, e que toda equipe colaboradora tenha essa postura. Qualquer falha pode causar consequências negativas para a organização.

8) A oitava é o trabalho em equipe - todos devem trabalhar juntos e comprometer-se em equipe para o sucesso da organização.

9) A nona é pesquisas com funcionários - não apenas os clientes devem ser pesquisados com relação a satisfação, mas os funcionários também, quanto a estarem satisfeitos, serem motivados e atender suas necessidades dentro da organização.

10) E por fim, a décima a liderança de servidores - a liderança dentro da organização é fundamental para bons resultados, tanto entre chefe e colaborados, quanto de colaboradores com clientes. (LAS CASAS, 2006, p. 99).

Destarte, estas lições supracitadas, podem ajudar a organização a corrigir falhas, melhorar serviços e alcançar resultados positivos para a organização.Kotler (2000, p. 58) define que satisfação "consiste na sensação de prazer ou desapontamento resultante da comparação do desempenho (ou resultado) percebido de um produto em relação às expectativas do comprador". Segundo Detzel e Desatick (1995, p. 58 apud MANDELLI, 2014, p. 16):

Satisfação do cliente é o grau de felicidade experimentada por ele. Ela é produzida por toda uma organização - por todos os departamentos, todas as funções e todas as pessoas. Entre os clientes se incluem os compradores externos de bens e serviços da organização, fornecedores, a comunidade local, funcionários, gerentes e supervisores (e acionistas, se a organização for de capital 
aberto).

Kotler e Keller (2013, p. 142 apud MIRANDA e SIMÃO, 2015, p. 89) utilizam novas terminologias para definir o grau de interação entre empresa e 0 cliente a partir da definição da qualidade da satisfação dos consumidos de suas necessidades e expectativas. A satisfação para eles foi definida como uma forma de suprir as necessidades dos clientes. O encantamento é o grau máximo de satisfação que transforma o cliente um divulgador para empresa no mercado, favorecendo-o.

Frances e Roland Bee (2001, p. 15 apud JUNIOR e OLIVEIRA, 2015) citam motivos que definem a importância do atendimento ao cliente. O primeiro motivo é o cliente estar satisfeito, isso, provoca menos estresse. Não saber identificar as causas da insatisfação pode causar um desconforto. Já o cliente satisfeito causa menos problemas, mas ao ficar mais tempo com o cliente podem surgir problemas decorrentes da demora e espera. Clientes são seres humanos, logo, atenção, eficiência e presteza são admiráveis.

Enfim, a empresa sem o cliente não existe, indivíduo este, importante para o seu crescimento e manutenção no mercado competitivo.

\section{METODOLOGIA}

Trata-se de uma pesquisa do tipo descritiva e estudo de caso, com fundamentos bibliográficos, tendo como técnica de coleta de dados 0 questionário estruturado, e por fim a análise dos dados por meio de estatística descritiva simples.

De acordo Gil (2009. p. 6), são várias as definições a respeito sobre "estudo de caso", e não existe ainda um consenso entre os autores sobre delimitar uma única fórmula para sua definição. Para Yin (2009, p. 24), "o estudo de caso é usado para contribuir ao nosso conhecimento dos fenômenos individuais, grupais, organizacionais, sociais, políticos e relacionados". Nesse contexto, este trabalho é um estudo de caso único que segundo Yin (2009, p. 201) trata-se de "uma única narrativa é usada para descrever e analisar o caso".

Para que haja uma confiabilidade dos dados coletados, foi realizado o 
protocolo de estudo de caso segundo Yin (2009, p. 106): "é uma maneira importante de aumentar a confiabilidade da pesquisa de estudo de caso e se destina a orientar o investigador na realização da coleta de dados de um caso único".

A pesquisa também apresenta caráter descritivo que, segundo Gressler (2003, p. 59), é "a pesquisa que descreve fatos e características presentes em uma determinada população ou área de interesse". Para Veal (2011, p. 29), "esta pesquisa procura descobrir, descrever ou mapear padrões de comportamentos em áreas ou atividades que não foram previamente estudados”. Já segundo Gil (2009, p. 42), “a pesquisa descritiva tem como objetivo primordial a descrição das características de determinada população ou fenômeno, então, o estabelecimento de relação entre vaiáveis".

A coleta de dados é umas das partes mais importantes da pesquisa; é onde se obterá os dados necessários para corresponder ao que se quer saber. Neste trabalho, isso foi realizado por meio de um questionário estruturado, que foi aplicado junto aos clientes que utilizam os serviços oferecidos pela empresa, durante cinco dias no horário das 8:00 ao 12:00h, tendo como finalidade a obtenção das respostas relacionadas ao que se busca.

Conforme Gil (2002, p. 116), "a elaboração do questionário consiste basicamente em traduzir os objetivos específicos da pesquisa em itens bem redigidos". Foram aplicados 80 questionários aos clientes da Loja Airam (nome fantasia), situada na cidade de Capela - SE. O questionário possui 25 perguntas fechadas e foram entregues presencialmente aos clientes que aceitaram responder voluntariamente, que além da carta explicativa, foram informados sobre a importância de se responder o questionário para a realização da pesquisa. A aplicação foi realizada entre os dias 14 e 20 de março de 2017, das 8:00 às 12:00 horas. A estratégia adotada para a aplicação do questionário foi a abordagem pessoal e aleatória com os clientes no momento de suas visitas à organização. Em primeiro lugar, foi explicado aos clientes os objetivos da pesquisa e em seguida, os mesmos foram convidados a responder o questionário de forma voluntária e anônima, para preservar suas identidades. Em relação ao embasamento teórico da pesquisa, o percurso para os dados serem fundamentados foi por intermédio da pesquisa bibliográfica 
para apoiar a análise e interpretação dos dados coletados. A pesquisa bibliográfica permite "colocar o pesquisador em contato direto com tudo o que foi escrito, dito ou filmado sobre determinado assunto" (MARCONI e LAKATOS, 2010, p. 57). Conforme Gil (2002, p. 44), “a pesquisa bibliográfica é desenvolvida com base em material já elaborado, constituído principalmente de livros e artigos científicos".

O local de estudo da presente pesquisa foi uma empresa privada do município de Capela, estado de Sergipe.

\section{ANÁLISE DE DADOS}

A seguir são apresentadas as características que descrevem o perfil dos clientes entrevistados. A Tabela 1 mostra que, dentre os clientes entrevistados, apenas dois foram do sexo masculino e 78 do sexo feminino representando a maioria dos clientes com 97,50\%. Nesse aspecto, a empresa pode traçar metas e produtos mais direcionados a este público específico.

Tabela 1 - Sexo dos respondentes.

\begin{tabular}{ccc}
\hline Sexo & Questionados & Percentual \% \\
\hline Masculino & 2 & 2,50 \\
Feminino & 78 & 97,50 \\
Total & 80 & 100,00 \\
\hline
\end{tabular}

Fonte: Dados da pesquisa (2019).

Na Tabela 2, serão apresentados os dados relacionados ao estado civil dos clientes.

Tabela 2 - Estado civil dos respondentes.

\begin{tabular}{ccc}
\hline Estado civil & Questionados & Percentual \% \\
\hline Solteiro & 29 & 36,25 \\
Casado & 30 & 37,50 \\
Separado & 0 & 0,00 \\
Viúvo & 8 & 10,00 \\
Outros & 13 & 16,25 \\
Total & 80 & 100,00 \\
\hline
\end{tabular}


Fonte: Dados da pesquisa (2019).

O maior percentual apresentando foi o de casado (a), com 37,50\%, sendo que solteiro apresentou 36,25\%.

Tabela 3 - Faixa etária dos respondentes.

\begin{tabular}{lll}
\hline Faixa etária & Participantes & Percentual \% \\
\hline Até 20 anos & 9 & 11,25 \\
$21-30$ anos & 25 & 31,25 \\
$31-40$ anos & 21 & 26,25 \\
$41-50$ anos & 11 & 13,75 \\
Acima de 50 anos & 14 & 17,50 \\
Total & 80 & 100,00
\end{tabular}

Fonte: Dados da pesquisa (2019).

Observou-se que $11,25 \%$ possui até 20 anos, 31,25\% entre 21 e 30 anos, com 26,25\% entre 31 e 40 anos, 13,75\% encontram-se entre 41 e 50 anos, e 17,50\% possuem mais de 50 anos de idade, mostrando que o público predominante é entre 21-30 anos, ou seja, um público jovem. A partir desta informação, a empresa pode traçar estratégias que possam atrair este público, a partir de pesquisas de opinião ou pesquisas que indiquem produtos que são mais atraentes para os mesmos.

Percebeu-se que apenas $20 \%$ dos clientes possuem até o ensino fundamental completo, 63,75\% dos clientes (a maioria) concluíram o ensino médio, 6,25\% possuem ensino superior incompleto, 3,75\% possuem ensino superior completo e cinco dos clientes responderam ter pós-graduação correspondente a $6,25 \%$ da amostra.

Tabela 4 - Renda média dos respondentes.

\begin{tabular}{ccc}
\hline Escolaridade & Participantes & Percentual \% \\
\hline Até 1 salário mínimo & 53 & 66,25 \\
De 1 a 3 salários mínimos & 25 & 31,25 \\
De 3 a 5 salários mínimos & 2 & 2,50 \\
De 5 a 7 salários mínimos & 0 & 0,00 \\
$>$ de 7 salários mínimos & 0 & 0,00 \\
Total & 80 & 100,00 \\
\hline
\end{tabular}


Fonte: Dados da pesquisa (2019).

Percebe-se que $66,25 \%$ dos clientes possuem renda inferior a 1 salário mínimo. A faixa de renda de 1 até 3 salários mínimos corresponde à $31,25 \%$ da amostra; 2,5\% apresentam renda de 3 até 5 salários mínimos; o valor entre 5 e 7 salários e acima de 7 salários mínimos nenhum dos questionados.

Em síntese, o perfil dos clientes da empresa é o público feminino, faixa etária jovem de 21 a 30 anos, predominantemente com escolaridade de ensino médio completo e renda em média de até um salário mínimo.

Na próxima etapa são apresentados os dados obtidos na segunda etapa da pesquisa.

\subsection{SERVIÇOS E PRODUTOS}

Nesta etapa, investigou-se sobre os produtos/serviços da empresa, em que as respostas sobre a satisfação foram escalonadas por intermédio da Escala de Lickert, para verificar o indicativo de níveis satisfatórios, em que 1 correspondente a nunca, 2 pouco, 3 às vezes, 4 muito e 5 sempre.

A Figura 1 apresenta a percepção dos clientes a respeito do serviço/produto, especificamente, se o mesmo atende às suas necessidades.

Figura 1 - Serviços/produtos relacionados às necessidades dos clientes.

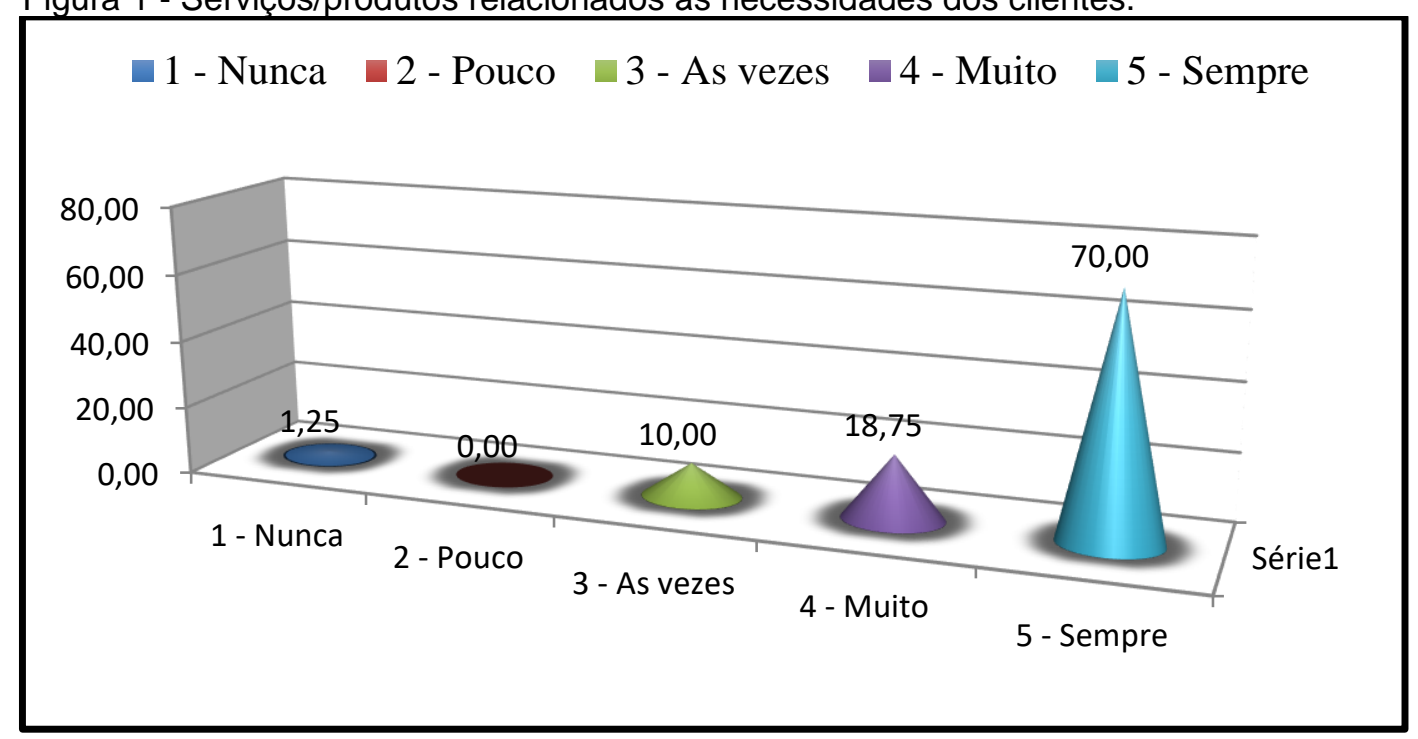

Fonte: Dados da pesquisa (2019).

Pode-se observar que $70 \%$ dos clientes afirma que a qualidade dos produtos/serviços oferecidos sempre atende suas necessidades, um percentual 
bastante representativo para empresa, pois atender e satisfazer o cliente são os melhores objetivos para seu crescimento.

A seguir, a Figura 2 apresenta a qualidade dos produtos/ serviços na percepção dos clientes.

Figura 2 - Qualidade dos produtos/serviços.

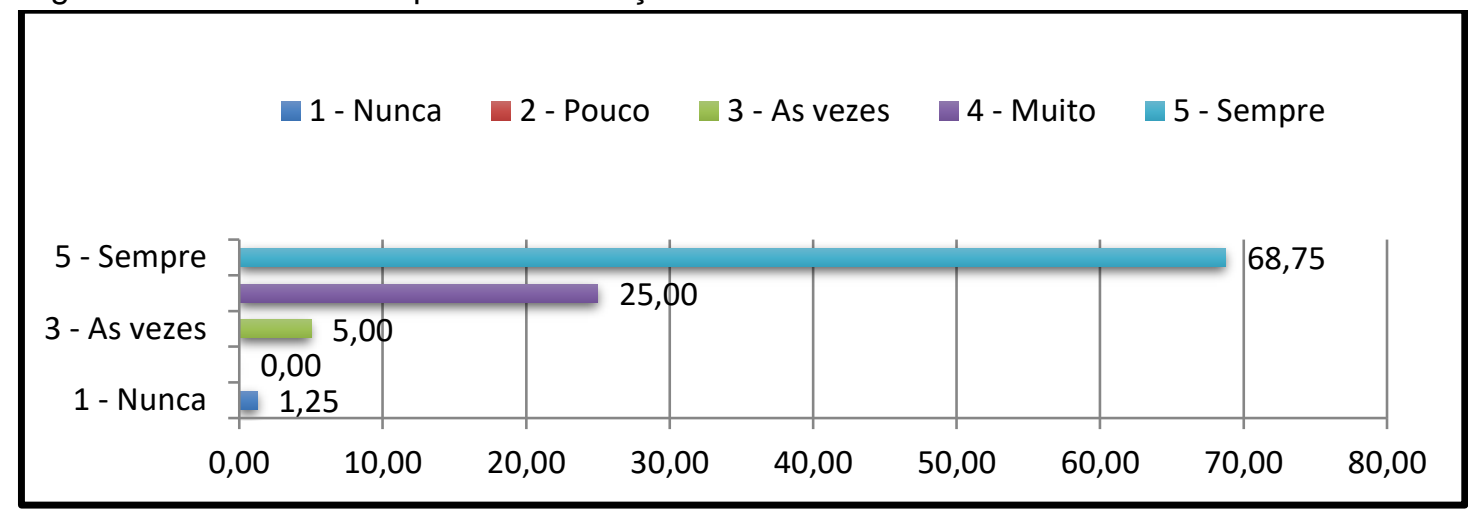

Fonte: Dados da pesquisa (2019).

Conforme a Figura 3, a qualidade dos produtos/serviços oferecidos pelas empresas é satisfatória, pois 68,75\% afirmam que a empresa sempre oferece tal característica. Neste aspecto, confirma-se o pensamento de Kotler (2002) ao afirmar que a qualidade está nos olhos de quem vê, ou seja, do cliente.

Qualidade é a filosofia que surge do valor que uma empresa busca para melhor atender as necessidades e expectativas de seus clientes internos e externos. A sobrevivência das empresas torna-se mais árduas pela necessidade de atender às demandas de uma sociedade cada vez mais consciente de seus direitos. As incertezas e os novos desafios deixam o futuro das empresas altamente dependentes das formas pelas quais operam e se transformam. Assim, a busca da qualidade e da plena satisfação do cliente exige novas técnicas, conhecimentos e habilidades (SILVA e SCHIMIDT, 1998, p. 6 apud MANDELLI, 2014).

Portanto, na percepção dos clientes, os preços favoráveis dos produtos/ serviços são sempre bem-vindos, não só a qualidade dos produtos é fundamental, mas também os preços são considerados bastante importantes para satisfação.

Ademais, quando a questão é valor, isso influencia diretamente os clientes, pois, a facilidade de pagamentos, os descontos, o preço melhor (ou mais baixo) que os dos concorrentes e o preço (justo) de acordo aos produtos, 
podem refletir diretamente no interesse do cliente por determinada organização.

Em sequência, a Tabela 5 apresenta a percepção detalhada dos clientes em relação aos preços.

Tabela 5 - Valores e facilidade de pagamento.

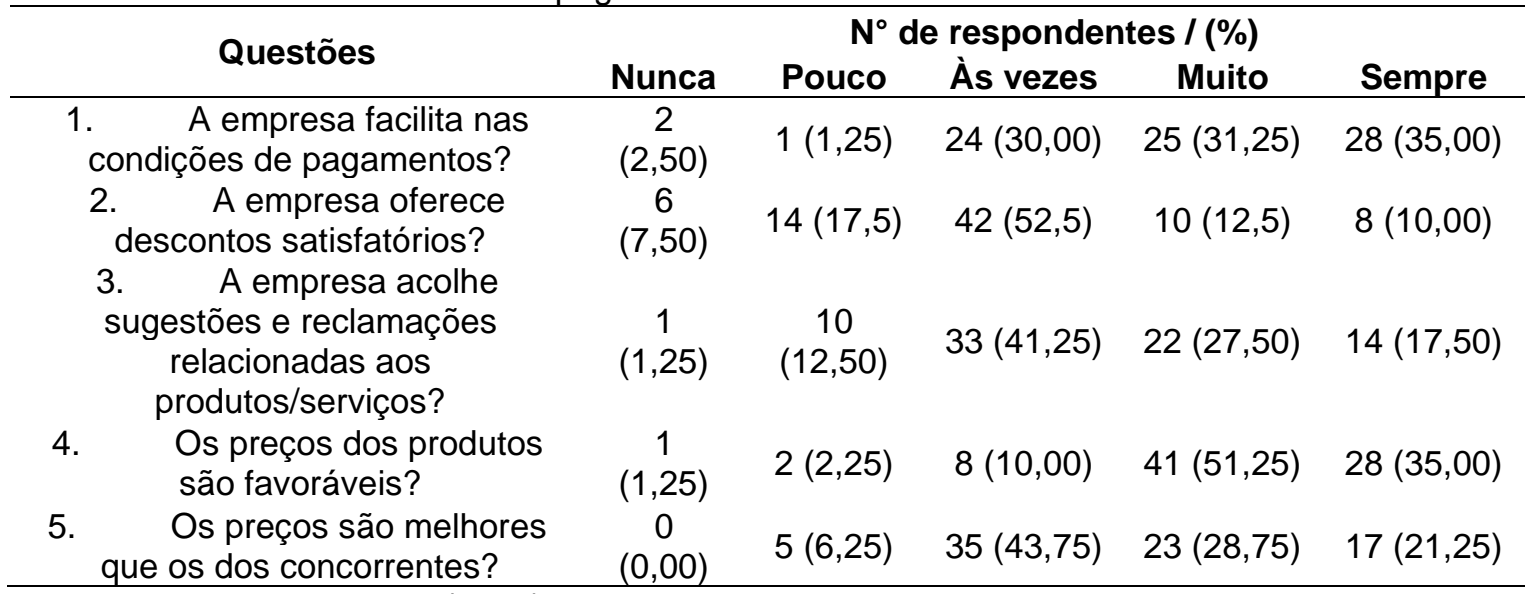

Fonte: Dados da pesquisa (2019).

Podemos observar que quanto às condições do pagamento, em relação ao nível de satisfação 35\% mostram-se sempre satisfeitos, apesar disso, podemos observar que $31,25 \%$ estão muito satisfeitos e $30 \%$ consideram-se satisfeitos apenas às vezes. Podemos verificar que há uma pequena diferença nesses níveis de satisfação, apesar do maior percentual dos questionados sempre estarem satisfeitos. Isto reflete também na sexta questão em que $52,5 \%$ estão satisfeitos apenas "às vezes" com os descontos oferecidos pela empresa é considerado um ponto negativo, pois em geral, os clientes apreciam descontos satisfatórios. Nesse aspecto, Gomes (2005 apud Lima, 2016) atenta ao fato de que políticas de descontos e condições de pagamento podem ser maneiras de fidelizar o cliente, uma vez que a clareza dessas condições torna a relação cliente e empresa mais firme e confiável.

Já na quinta questão desta etapa, questionou se a empresa acolhe sugestões e reclamações de algo que seja agradável ao cliente. Para o cliente é sempre bom ser ouvido em relação aos produtos/serviços oferecidos. Isso, pode ajudar a identificar suas necessidades, ou seja, entender o cliente e satisfazê-lo.

$\mathrm{Na}$ questão cinco da Tabela 6, percebe-se que, dos clientes 
entrevistados 33\% afirmam que "às vezes" suas sugestões e reclamações são atendidas, questão essa muito importante, pois clientes ouvidos pela organização podem se tornar clientes fiéis, por sentirem aceitação e credibilidade nas suas solicitações. A partir disso, a empresa pode analisar as informações para assim, buscar melhorias nos serviços/produtos oferecidos para melhor atendê-los, de forma direcionada e eficaz.

Podemos observar também que na questão 6 que $51,25 \%$ consideram muito satisfatório os preços dos produtos, opinando como "justo". Apesar desse percentual, na sétima questão $43,75 \%$ consideram os preços "às vezes" um pouco melhor (ou mais baixo) que os dos concorrentes. Segundo Praxedes (2007 apud Lima 2016) a estratégia de adequação de preços é considerada fundamental para a posição de mercado, pois os preços interferem na maneira de como as empresas competem e também na atração de clientes para dentro da loja.

$\mathrm{Na}$ terceira etapa da pesquisa, foram analisados: o atendimento oferecido pela empresa, o atendimento dos recepcionistas/atendentes, a atenção recebida pelos funcionários, a comunicação, o tempo de atendimento e a receptividade.

A Figura 3 apresenta os resultados referentes a percepção dos clientes em relação ao atendimento em geral.

Figura 3 - Atendimento da empresa.

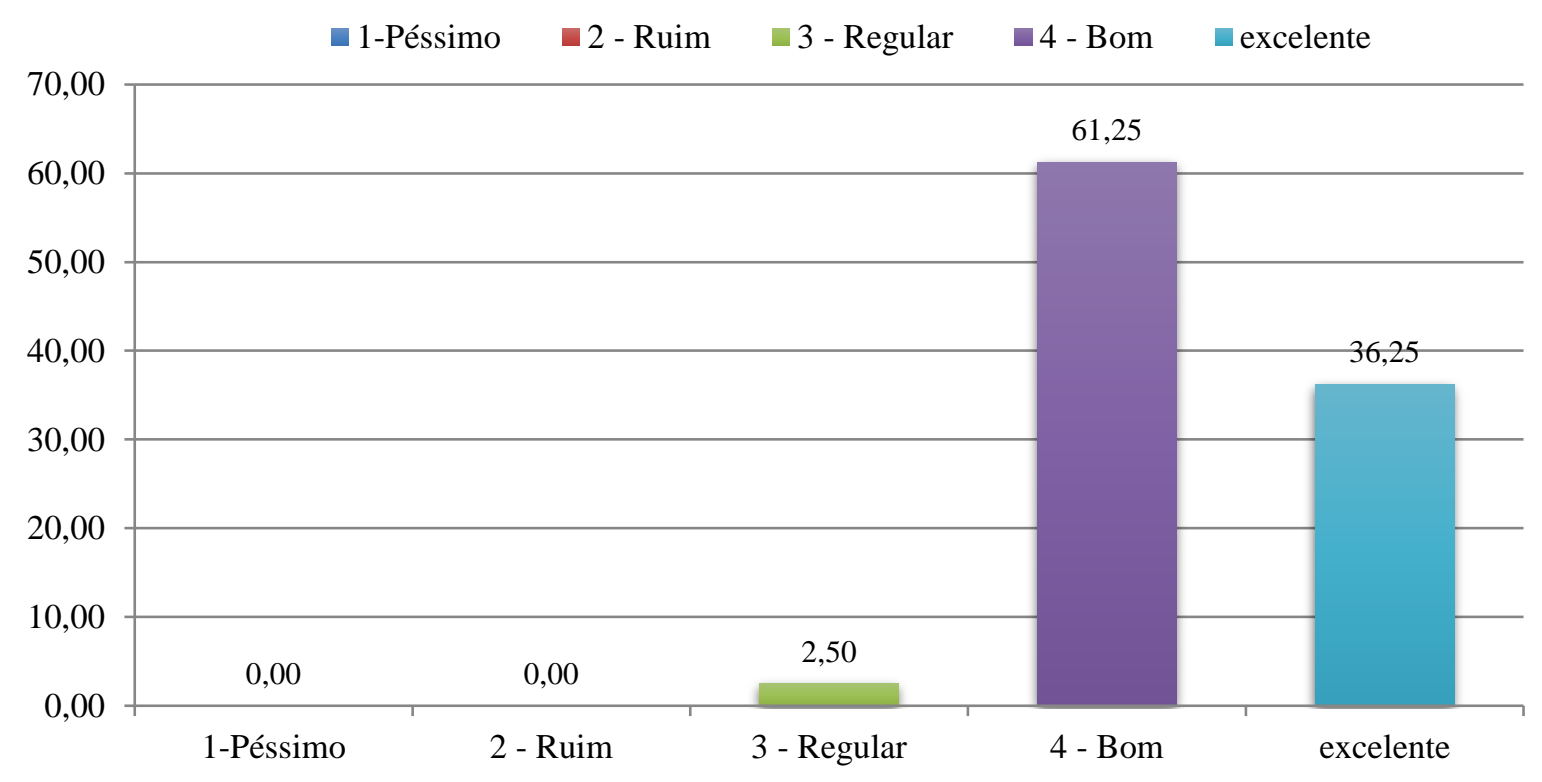


Fonte: Dados da pesquisa (2019).

O atendimento oferecido pela empresa é considerado bom por um percentual bastante representativo. $61,25 \%$ consideram o atendimento bom, já 36,25 consideram excelente. Isso se torna um fator muito importante, contribuindo para que o cliente continue fiel a empresa, e volte sempre por ser bem atendido, como afirma Torres e Fonseca (2012 apud LIMA, 2016) que ressaltam que "fidelizar é encantar o cliente, é surpreendê-lo com o diferencial.

A Tabela 6 apresenta a análise dos níveis de satisfação da terceira etapa do questionário, também relacionadas ao atendimento.

Tabela 6- Atendimento oferecido pela empresa.

\begin{tabular}{|c|c|c|c|c|c|}
\hline \multirow{2}{*}{ Questões } & \multicolumn{5}{|c|}{$\mathrm{N}^{\circ}$ de respondentes/(\%) } \\
\hline & Péssimo & Ruim & Regular & Bom & Excelente \\
\hline Serviços & & & & $\begin{array}{l}30 \\
(37,50)\end{array}$ & $50(62,50)$ \\
\hline Comunicação & & & $1(1,25)$ & $\begin{array}{l}35 \\
(43,75)\end{array}$ & $44(55,00)$ \\
\hline Tempo de atendimento & & $1(1,27)$ & $4(5,06)$ & $\begin{array}{l}45 \\
(56,96)\end{array}$ & $29(36,71)$ \\
\hline Atenção recebida & & $1(1,25)$ & $4(5,00)$ & $\begin{array}{l}27 \\
(33,75)\end{array}$ & $48(60,00)$ \\
\hline Receptividade & & & $3(3,75)$ & $\begin{array}{l}30 \\
(37,50)\end{array}$ & $47(58,75)$ \\
\hline
\end{tabular}

Fonte: Dados da pesquisa (2019).

Nota-se que $62,50 \%$ dos pesquisados afirmaram receber um excelente atendimento por parte dos atendentes, dados satisfatórios em relação ao nível de satisfação. 37,50 \% consideram o atendimento bom; logo, para a organização, isso demonstra que os serviços realizados pelos atendentes são eficientes.

Quanto à comunicação entre clientes e atendentes, 55,00\% dos clientes consideram excelente, e 43,75\% consideram bom. Sendo assim, confirma-se que a comunicação é importante para que o cliente se sinta "à vontade" no ambiente da empresa.

Em relação ao tempo de atendimento, 56,96 \% consideram bom e $36,71 \%$ excelente. Poucos clientes consideram regular e ruim; e nenhum dos interrogados consideram péssimo o tempo para serem atendidos. No quesito atenção recebida, $60,00 \%$ consideram excelente; fato considerado muito 
apropriado, e 58,75\% consideram excelente quanto a receptividade feita pelos atendentes, também um nível muito adequado para a empresa.

Portanto, com essas análises, a empresa pode-se considerar excelente quanto ao atendimento oferecido, na percepção dos clientes. Contudo, não se pode deixar de tratar o atendimento como fator imprescindível, realizando sempre investimentos e estratégias neste aspecto, para que o cliente continue sempre satisfeito e fiel à empresa.

$\mathrm{Na}$ etapa seguinte será analisado sobre a satisfação do cliente com ambiente da empresa.

\subsection{AMBIENTE DA EMPRESA}

Na quarta etapa da pesquisa, buscou-se avaliar o nível de satisfação dos clientes em relação ao ambiente da empresa, usou-se o mesmo procedimento das etapas anteriores quanto a respostas dos clientes questionados, sendo avaliados os níveis na escala: péssimo, ruim, regular, bom e excelente.

Tabela 7 - Ambiente da empresa.

\begin{tabular}{|c|c|c|c|c|c|}
\hline \multirow{2}{*}{ Questões } & \multicolumn{5}{|c|}{$\mathrm{N}^{\circ}$ de respondentes/ (\%) } \\
\hline & Péssimo & Ruim & Regular & Bom & Excelente \\
\hline Ambiente da empresa & & & $2(2,50)$ & $58(72,50)$ & $20(25,00)$ \\
\hline Localização & & & $1(1,25)$ & $57(71,25)$ & $22(27,50)$ \\
\hline Iluminação & & & $1(1,25)$ & $62(77,50)$ & $17(21,25)$ \\
\hline Estrutura física & & & $2(2,50)$ & $59(73,75)$ & $19(23,75)$ \\
\hline Limpeza & & & $1(1,25)$ & $57(71,25)$ & $22(27,50)$ \\
\hline Organização & & & $0(0,00)$ & $58(72,50)$ & $22(27,50)$ \\
\hline
\end{tabular}

Fonte: Dados da pesquisa (2019).

O ambiente da empresa contribui para que o cliente se sinta satisfeito ao frequenta-la, diante disso. Logo, a primeira questão buscou averiguar qual o nível de satisfação relacionado ao ambiente da empresa. Para Dantas (2010), os aspectos físicos da empresa são os primeiros contatos que os clientes têm antes dos atendentes, e isso se torna impactante para o cliente. Dos 80 clientes questionados, $72,5 \%$ consideram bom, em seguida com $25 \%$ 
consideraram excelente, 2,5\% regular e nenhum cliente considerou ruim ou péssimo. Para empresa, trata-se de outro ponto consideravelmente positivo, pois, o cliente mantém-se mais confortável para comprar, estando satisfeito no local que se encontra, assim, ele tem grande possibilidade de retornar.

Quanto a sua localização, este aspecto é considerado como bom por $71,25 \%$ dos clientes, a iluminação também é considerada boa por $77,5 \%$. Sua estrutura física é considerável, sendo 73,75\% bom pelos clientes consumidores. A organização da empresa também é considerada boa com $72,5 \%$ de clientes satisfeitos.

Relacionado também ao ambiente da empresa podemos observar que o cliente é totalmente satisfeito em todos os questionamentos relacionados, pode-se observar um nível considerado equilibrado. Assim, atender as necessidades e desejos dos clientes, sempre investindo esforços com 0 objetivo de manter uma relação duradoura com os seus clientes, buscando cada vez mais satisfazê-los e fidelizá-los, é necessário para a empresa se mantenha firme no mercado.

\section{CONSIDERAÇÕES FINAIS}

Esse estudo teve como objetivo identificar a visão dos clientes sobre os aspectos relacionados a qualidade do atendimento dentro da empresa, os serviços/produtos oferecidos e ambiente da empresa. Tratou-se de um estudo de caso único, realizado em uma empresa privada de médio porte no município de Capela, estado de Sergipe.

Foi possível analisar a percepção dos clientes em relação ao nível geral de satisfação dos clientes sobre o atendimento e aos produtos/serviços da empresa. Em geral, os dados apontam uma forte exigência dos clientes em relação a diversos fatores que podem influenciar na sua satisfação. Em relação ao nível geral sobre os serviços e produtos oferecidos, a pesquisa verificou que, a maioria dos clientes encontra-se satisfeitos com os serviços e produtos oferecidos. Porém, sobre a questão preço, para os clientes os descontos são considerados insatisfatórios. Assim, a empresa deve rever sugestões, até por parte dos clientes para que assim, possam melhor satisfazê-los. 
A pesquisa contribuiu também, para fins de aplicação dos seus resultados na área empresarial, como um diagnóstico para que a empresa possa melhorar suas estratégias e táticas relacionadas a atração e fidelização de clientes. Ademais, confirma-se a importância do tema para empresas de qualquer porte e segmento. Além disso, esta pesquisa traz contribuições e reflexões para a área de Secretariado Executivo, já que este profissional atua diretamente com atendimento a clientes internos e externos de diversas organizações, sendo um profissional-chave para o sucesso do atendimento e "encantamento" de clientes. Para a área acadêmica, o estudo possibilita obter uma visão da importância do tema estudado, expandindo reflexões e instigando futuras investigações a serem realizadas em empresas de outros segmentos seja da área privada ou pública.

Também é importante observar na discussão os motivos pelos quais foram abordadas questões sobre o perfil dos sujeitos pesquisados. Dados que são relevantes ao se considerado importante em qualquer empreendimento, pois ao conhecer o perfil dos seus clientes a empresa pode realizar melhores atendimentos e pesquisas de marketing sobre o público considerado.

Por fim, conclui-se que o atendimento ao cliente é fundamental para o fortalecimento das organizações e para sua estabilidade no atual mercado competitivo empresarial.

Para estudos futuros, sugere-se que novas pesquisas sejam realizadas em empresas de pequeno porte, verificando a percepção dos clientes e também dos funcionários sobre a visão do atendimento ao cliente e técnicas para desenvolver melhor esta habilidade nas organizações.

\section{REFERÊNCIAS}

ANTUNES, E. V.; et al. A Implementação da Pós-Venda na Empresa Ps Pneus em Guarapuava/PR: um estudo proposto pela área de assessoria. Revista de Gestão e Secretariado - GeSec, São Paulo, v. 3, n. 2, p 24-46, jul./dez. 2012. (2012). Recuperado em 10 de dezembro, 2017, de:

https://www.revistagesec.org.br/secretariado/article/view/104/0

BENTES, O. Atendimento ao Cliente. Curitiba: IESDE. 2010. 
COSTA, C. U; NAKATA Y. U; CALSANI J. R. S. Qualidade no atendimento: a influência do bom atendimento para conquistar clientes. Rev. Científica

Eletrônica UNISEB, Ribeirão Preto, v.1, n.1, pp. 54-65. 2013. Recuperado em 18 março, 2017, de: <

http://uniseb.com.br/presencial/revistacientifica/arquivos/4.pdf>.

DANTAS, E. B. Atendimento ao público nas organizações: quando o marketing de serviços mostra a cara. Brasília: Editora Senac DF, 2010.

GRESSLER, A. L. Introdução e Projetos e Relatórios. São Paulo. Editora: Layola, 2003.

GIL, A. C. Como Elaborar Projetos de Pesquisa. São Paulo: Atlas, 2010.

KOTLER, P. Administração de marketing: a edição do novo milênio. Tradução: Bazán Tecnologia e Linguística. São Paulo: Prentice Hall,2000.

KOTLER, P. Marketing de Serviços Profissionais. São Paulo: Manole Ltda, 2002.

LAS CASAS, A. L. Marketing de Serviços. São Paulo: Atlas, 2006.

MACHADO, R. de O.; ANGNES, J. S.; PIMENTEL, M. E. B.; MAZUR, L. Satisfação No Atendimento: um Estudo Na Empresa JM Alarmes em Guarapuava/Pr. Revista de Gestão e Secretariado - GeSec. São Paulo, v. 4, n. 2, pp. 151-176, 2013.

MANDELLI, A. da S. Qualidade no atendimento ao cliente. Monografia. Curso de Administração de Empresas. Universidade do Extremo Sul Catarinense - UNESC. 40 f, 2014.

MARCONI, M. de A., LAKATOS, E. M. Técnicas de Pesquisa: Planejamento e execução de pesquisa,amostragem e técnicas de pesquisa, elaboração, análise e interpretação de dados. São Paulo: Atlas, 2010.

MIRANDA, A. C. T., SIMÃO, B. E. A. Perspectivas da Qualidade no Atendimento aos Clientes: Um Estudo de caso na Empresa Federal Bar e Lanchonete de Iturama - MG. Revista Organizações e Sociedade Multidisciplinar, Iturama, MG, V. 4, n. 1, pp. 85-98, 2015. 
PEREIRA, R. B. G.; MOREIRA, N. C. Qualidade no Atendimento: uma avaliação bibliométrica nos periódicos científicos nacionais (1997-2013).

Revista de Gestão e Secretariado - GeSec, São Paulo, v. 6, n. 1, p 126-149, jan./abr, 2015.

LIMA, N. S. Ações de marketing de relacionamento: um estudo em micro e pequenas empresas do seguimento de produtos naturais. Trabalho de Conclusão de Curso. Universidade Federal de Sergipe. São Cristóvão, SE, 77 f, 2016.

VEAL, A. J. Metodologia de Pesquisa em Lazer e Turismo. São Paulo: Editor Aleph Ltda, 2011.

YIN, R. K. Estudo de Caso: planejamento e métodos. Porto Alegre: Bookman, 2009. 